\title{
Influence of the State of Fimbriation on Transmission of the Colicinogenic Factor coll between Strains of Shigella flexneri
}

\author{
By M. MULCZYK* AND J. P. DUGUID \\ Bacteriology Department, University of St Andrews, Queen's College, Dundee
}

(Received 19 April 1966)

\begin{abstract}
SUMMARY
The colicinogenic factor colI derived from Shigella sonnei colicine type 2 (Abbott \& Shannon, 1958) was transmitted between different strains of Shigella flexneri in serotypes 1a, 1b, 2a, 2b, 3a, 3c, 4a, 4b, 4c, 5a, X and Y when donor and acceptor strains were grown together in mixed culture in aerobic static broth for a period of $20 \mathrm{hr}$ or $48 \mathrm{hr}$ at $37^{\circ}$. The rate of transfer was influenced by the state of fimbriation of the acceptor bacteria, but not by that of the donor bacteria. The proportion of acceptor organisms acquiring coll was very high, e.g. 15-40\% in $20 \mathrm{hr}$ and $50-95 \%$ in $48 \mathrm{hr}$, when the acceptor was genotypically fimbriate and in the fimbriate phase $\left(\mathbf{F i m}^{+} \mathbf{F}\right)$; but it was much lower, e.g. $0-5 \%$ in $20 \mathrm{hr}$ and $1-15 \%$ in $48 \mathrm{hr}$, when the acceptor was either genotypically non-fimbriate $\left(\mathrm{Fim}^{-}\right)$or genotypically fimbriate but in the non-fimbriate phase $\left(\mathrm{Fim}^{+N}\right)$. Although it facilitated the transmission of colI, the presence of fimbriae was not essential for transmission, since transmission at a low rate was obtained in most crosses of $\mathrm{Fim}^{-}$donors with $\mathrm{Fim}^{-}$acceptors. Only 1 out of 17 strains of $S$. flexneri tested as acceptors failed to acquire $\operatorname{col} \boldsymbol{I}$ in any test. Transmission did not take place within the first $2 \mathrm{hr}$ of mixed culture; it occurred mainly during the period of slow growth after the end of the exponential phase (i.e. between 8 and $48 \mathrm{hr}$ ) when, with fimbriate organisms, a pellicle of bacteria had developed on the surface of the broth. The rate of transmission was very much decreased when pellicle formation was prevented by intermittent or continuous agitation of the culture. Experiments in which the donor bacteria were killed by adding streptomycin at $8 \mathrm{hr}$ showed that an extensive 'epidemic' spread of colI took place within the acceptor population during the later stages of culture. When stationary-phase (1-10 days) broth cultures of donor and acceptor bacteria were mixed together and incubated without the addition of fresh broth, the rates of transfer at 20 and $48 \mathrm{hr}$ were as high as in the mixed cultures grown from small inocula. Transmission also occurred with high frequency in a defined medium containing glucose, $\mathrm{NH}_{4}{ }^{+}$and nicotinic acid.
\end{abstract}

\section{INTRODUCTION}

Many strains of bacteria in different genera of Enterobacteriaceae possess the ability to produce and liberate colicines, antibiotic substances which are active against many other strains of enterobacteria (Fredericq, 1957, 1963). This ability may be transferred, during the conjugation of bacteria, from a colicinogenic to a

\footnotetext{
* Present address: Institute of Immunology and Experimental Therapy, Polish Academy of Sciences, Wroclaw, Poland.
} 
non-colicinogenic strain (Fredericq, 1954; Ozeki, Howarth \& Clowes, 1961). The colicinogenic factor that is transferred from bacterium to bacterium has the properties of a plasmid, i.e. an autonomously reproducing cytoplasmic hereditary determinant (Lederberg, 1952), and the transfer of colicinogeny is not dependent on transfer of the bacterial chromosome as in the classical recombination phenomenon. Factors influencing the frequency of transfer of colicinogenic factor I ( colI), which determines the production of colicine I, have been investigated by Ozeki, Stocker \& Smith (1962) and Stocker, Smith \& Ozeki (1963) in experiments with Salmonella typhimurium carrying colI derived from Shigella sonnei strain P 9.

The present work was done in an attempt to discover whether the transfer of colI factors is influenced by the presence of fimbriae in the donor and acceptor bacteria. Fimbriae are non-flagellar filamentous appendages that are present in many strains of most genera of enterobacteria and which confer adhesive properties on the bacteria; fimbriate bacilli are known to adhere to red blood cells, causing haemagglutination, and to other kinds of animal, plant and fungal cells (Duguid, Smith, Dempster \& Edmunds, 1955). It seemed possible that they might have an important role in effecting the conjugation of bacteria that is necessary for the transfer of colI. Cultures of Shigella flexneri were considered to be especially suitable for use in the investigation of the influence of fimbriation on the transfer of colI because both genotypically fimbriate $\left(\mathrm{Fim}^{+}\right)$and genotypically non-fimbriate (Fim-) strains occur in several serotypes of the species, and because cultures of the genotypically fimbriate strains can be grown in either a fimbriate $\left(\mathrm{Fim}^{+} \mathrm{F}\right)$ or a non-fimbriate $\left(\mathrm{Fim}^{+} \mathrm{N}\right)$ phenotype, or 'phase' (Duguid \& Gillies, 1957). Comparative experiments can, therefore, be made with comparable fimbriate and non-fimbriate cultures.

\section{METHODS}

Colicinogenic factors. Most of the experiments were made with colI factor derived from Shigella sonnei strain 2, the standard colicine secretor strain no. 2 of Abbot \& Shannon (1958), ref. no. 10047 of the Dysentery Reference Laboratory (DRL), Colindale, London. This factor, colI-CT2 is referred to as colI throughout the present paper.

For the purpose of comparison, a few experiments were made with the different colI factor, designated in this paper as $\operatorname{col} I-\boldsymbol{P} 9$, which had been studied by Stocker et al. (1963). This factor was obtained from Salmonella typhimurium strain LT2 cysD-36 (colI-P9), which had been given the factor from $S$. sonnei strain $\mathrm{P} 9$, and was received from Dr B. A. D. Stocker. Both the colI donor strains, S. sonnei 2 and $S$. typhimurium LT 2 cysD-36 (colI-P9), were streptomycin-sensitive; the former was non-flagellate and non-fimbriate (Fim-) and the latter was flagellate and fimbriate $\left(\mathrm{Fim}^{+}\right)$.

Donor and acceptor strains of Shigella flexneri. These are listed, with their serotype and fimbriation genotype, in Table 1. Streptomycin-sensitive strains were used $a_{\mathbf{S}}$ donors of coll. The colicinogenic factor had been introduced into them from Shigella sonnei strain 2 or Salmonella typhimurium strain LT 2 cysD-36 (colI-P9). Where subsequently, in the tables and text, a strain is described as a 'donor', it is to be understood that it carries coll even although it is designated by its number, e.g. 1a1, without the suffix colI. 
Streptomycin-resistant strains were used as acceptors. All these strains were resistant to $1000 \mu \mathrm{g}$. streptomycin $/ \mathrm{ml}$. They did not produce detectable colicines and they were resistant to the colicines determined by colI (i.e. colI-CT2) and colI-P9. The original cultures of the acceptor strains (Table 1, second column) were colicineresistant but streptomycin-sensitive; streptomycin-resistant mutants were derived by selection in streptomycin broth and these mutants were used as the acceptors in the experiments.

Table 1. Donor (colicinogenic) and acceptor (non-colicinogenic) strains of Shigella flexneri used in the experiments

\begin{tabular}{|c|c|c|}
\hline $\begin{array}{l}\text { Designation of } \\
\text { strain }\end{array}$ & Parent strain* & Serotype \\
\hline
\end{tabular}

(a) Donor strains (streptomycin-sensitive)

\begin{tabular}{|c|c|c|}
\hline $1 \mathrm{a} 1 \mathrm{colI}$ & NCTC 8192 & $1 a$ \\
\hline lal $\operatorname{col} I-P 9$ & NCTC 8192 & 1a \\
\hline $2 a 1$ colI & NCTC 8204 & $2 a$ \\
\hline $2 \mathrm{~b} 1 \mathrm{coll}$ & NCTC 8518 & $2 \mathbf{b}$ \\
\hline $4 \mathrm{al} \operatorname{coll}$ & Edinburgh $4 \mathrm{a} 1$ & $4 a$ \\
\hline $4 \mathrm{e} 10 \mathrm{coll}$ & DRL $127 / 56$ & $4 \mathrm{c}$ \\
\hline $5 \mathrm{a} 3 \operatorname{colI}$ & NCTC 8523 & $5 \mathrm{a}$ \\
\hline
\end{tabular}

(b) Acceptor strains (streptomycin-resistant)

\begin{tabular}{|c|c|c|}
\hline $1 a 1$ & NCTC 8192 & $1 \mathbf{a}$ \\
\hline $1 \mathrm{bl}$ & Wrocław 6713 & $1 b$ \\
\hline $2 \mathrm{a} 1$ & NCTC 8204 & $\mathbf{2 a}$ \\
\hline $2 a 19$ & DRL E $/ 56 / 9$ & $2 a$ \\
\hline $2 \mathrm{~b} 1$ & NCTC 8518 & $2 b$ \\
\hline $3 a 106$ & NCTC 8664 & $3 a$ \\
\hline $3 c 2$ & Wroclaw $6713 \mathrm{M}$ & $3 c$ \\
\hline $4 a 1$ & Edinburgh $4 a 1$ & $4 a$ \\
\hline $4 a 2$ & Wrocław $4 a$ & $4 a$ \\
\hline $4 \mathrm{~b} 1$ & DRL $181 / 56$ & $4 b$ \\
\hline $4 \mathrm{~b} 3$ & DRL E $/ 56 / 6$ & $4 \mathrm{~b}$ \\
\hline $4 c 10$ & DRL 127/56 & $4 c$ \\
\hline $5 a 3$ & NCTC 8523 & $\mathbf{5 a}$ \\
\hline $5 a 4$ & NCTC 8524 & $\mathbf{5 a}$ \\
\hline $5 a 12$ & DRI $64 / 56$ & $\mathbf{5 a}$ \\
\hline x105 & DRL $208 / 63$ & $\mathbf{x}$ \\
\hline y3 & NCrC 1169 & $\mathbf{Y}$ \\
\hline
\end{tabular}

\footnotetext{
* Parent strains were non-colicinogenic and streptomycin-sensitive. Donor strains were derived from them by infection with colI or colI-P9, and acceptors were streptomycin-resistant mutants derived from them. NCTC $=$ National Collection of Type Cultures, Colindale, London. DRL $=$ Dysentery Reference Laboratory, Colindale, London.

+ Strain Wrocław $6713 \mathrm{~m}$ is a serological mutant derived from the serotype $1 \mathrm{~b}$ strain Wrocław 6713 (Mulezyk, 1960).
}

Indicator of colI. The indicator strain, sensitive to colicine I and used to detect it, was Escherichia coli strain k 12-Row (Fredericq; DRL 10044), received from Dr J. D. Abbott.

Culture media. The nutrient broth used was Difco heart infusion broth. Difco heart infusion agar plates were used with or without streptomycin (1 mg./ml.). The defined medium was the glucose ammonium salts minimal medium of Ozeki et al. (1962) supplemented with nicotinic acid $1 \mu \mathrm{g} . / \mathrm{ml}$. Trypsin was not used in media. 
Fimbriate and non-fimbriate cultures. Fimbriate-phase $(\mathbf{F i m}+\mathbf{F})$ cultures were obtained by serial culture of $\mathrm{Fim}^{+}$strains at $37^{\circ}$ in static tubes of $10 \mathrm{ml}$. broth. Non-fimbriate-phase $\left(\mathrm{Fim}^{+} \mathrm{N}\right)$ cultures were obtained by serial culture of $\mathrm{Fim}^{+}$ strains on plates of nutrient agar (Duguid \& Gillies, 1957). Before use, the cultures were tested for haemagglutinating activity with a $3 \%$ suspension of guinea-pig red cells (method of Duguid \& Gillies, 1957) to confirm that they were richly fimbriate or entirely non-fimbriate. The notation used to designate the fimbriation genotype and phenotype (phase) of donor and acceptor cultures is shown in Table 2 .

\section{Table 2. Designations used to indicate the state of fimbriation of donor and acceptor cultures}

Designation
Fim $^{-}$
Fim $^{+}$
Fim $^{+} \mathbf{N}$
Fim $^{+} \mathbf{F}$

Fimbriation status of culture

Genotype non-fimbriate

Genotype fimbriate

Genotype fimbriate but phenotype (or phase) non-fimbriate

Genotype fimbriate and phenotype (or phase) fimbriate

Preparation of inocula for mixed cultures. The mixed broth cultures in which transmission of colI was observed were inoculated with about $10^{7}$ bacteria of the donor strain and about $10^{7}$ bacteria of the acceptor strain. These bacteria were taken from $24 \mathrm{hr}$ broth cultures of predetermined fimbriation genotype and phenotype. Phenotypically fimbriate $\left(\mathrm{Fim}^{+} \mathrm{F}\right)$ cultures were obtained by carrying a $\mathrm{Fim}^{+}$ strain through 4 or 5 serial $48 \mathrm{hr}$ cultures in broth. Genotypically fimbriate but phenotypically non-fimbriate $\left(\mathrm{Fim}^{+} \mathrm{N}\right)$ cultures were obtained by making 4 or 5 serial $48 \mathrm{hr}$ cultures on agar plates. The final $48 \mathrm{hr}$ culture of the $\mathrm{Fim}^{+} \mathbf{F}$ or $\mathrm{Fim}^{+} \mathrm{N}$ organisms was subcultured in broth for $24 \mathrm{hr}$ to prepare the inoculum for the experimental mixed culture. $\mathbf{F i m}^{+} \mathbf{N}$ organisms remained in the non-fimbriate phase during this single $24 \mathrm{hr}$ period of growth in broth. Genotypically non-fimbriate $\left(\mathrm{Fim}^{-}\right)$organisms were inoculated into the mixed culture from a $24 \mathrm{hr}$ broth culture that had been inoculated from a $48 \mathrm{hr}$ broth culture.

Tests for transmission of coll in mixed cultures. Crosses were made by growing the donor and acceptor strains in mixed culture in aerobic static broth for 20 and $48 \mathrm{hr}$ periods at $37^{\circ} ; 10 \mathrm{ml}$. broth in a test-tube stoppered with cottonwool was incubated under ordinary aerobic conditions without disturbance by movement, mixing or artificial aeration. Because sampling of the culture for examination involved mixing and disruption of any surface pellicle, separate tubes of mixed cultures were grown from similar inocula for each time of sampling (usually 20 and $48 \mathrm{hr}$ ) so that the culture and pellicle remained undisturbed until the sample was taken.

After the culture had been inoculated with about $10^{7}$ donor bacteria and about $10^{7}$ acceptor bacteria and had been incubated for the test period, it was mixed thoroughly by drawing up and down in a pipette so that any surface pellicle and any deposit were completely and uniformly dispersed. Tenfold dilutions of the culture were then prepared in sterile saline and $0 \cdot 1 \mathrm{ml}$. volumes spread on plates of streptomycin nutrient agar. After incubation for $24 \mathrm{hr}$, the plates were treated with chloroform vapour for $30 \mathrm{~min}$. and then overlayed with a thin layer of nutrient agar ( $1 \%$ agar). They were dried and inoculated by flooding with a broth culture of the indicator strain, Escherichia coli $\mathrm{k} 12$-Row. After overnight incubation the 
proportion $(\%)$ of colonies that were colicinogenic, i.e. surrounded by zones of inhibition of growth of the indicator strain, was determined. Generally this result was based on the observation of 200-700 acceptor-strain colonies.

\section{RESULTS}

\section{Transfer of colI between genotypically fimbriate $\left(\right.$ Fim $\left.^{+}\right)$ strains of Shigella flexneri}

The first experiments were made with the streptomycin-sensitive Fim $^{+}$strain 1 1a1 of Shigella flexneri as donor of colI. This strain had been rendered colicinogenic by infection with colI from $S$. sonnei strain 2 . Like other Fim ${ }^{+}$strains of $S$. flexneri, it could be obtained in a fimbriate phase $\left(\mathrm{Fim}^{+} \mathrm{F}\right)$ by serial culture in broth and in a non-fimbriate phase $\left(\mathrm{Fim}^{+} \mathbf{N}\right)$ by serial culture on agar. The acceptor strain was a streptomycin-resistant mutant derived from the original streptomycin-sensitive non-colicinogenic stock of strain 1a1; it, too, could be obtained in a fimbriate and a non-fimbriate phase. Crosses of the donor and acceptor strains were tested by growing the two strains together in mixed cultures in tubes of $10 \mathrm{ml}$. nutrient broth

Table 3. Frequency of transfer of colI between fimbriate-phase $(F)$ and non-fimbriatephase $(N)$ organisms of the Fim ${ }^{+}$strains 1 a1 and $2 a 19$ of Shigella flexneri during growth in mixed culture in aerobic static broth for 20 or $48 \mathrm{hr}$ at $37^{\circ}$

Tubes of $10 \mathrm{ml}$. broth were inoculated with, per tube, $10^{7}$ bacteria of the donor (streptomycin-sensitive) culture and $10^{7}$ bacteria of the acceptor(stremptomycin-resistant) culture, and were then incubated without disturbance for either 20 or $48 \mathrm{hr}$; separate tubes were set up for each time of incubation. After growth, the culture was thoroughly mixed and dilutions of it plated on streptomycin agar so as to yield colonies derived only from the acceptor-strain bacteria. These colonies were tested for colicinogeny.

Viable count of streptomycin-resistant (acceptor strain)

$\overbrace{\begin{array}{c}\text { Donor } \\ \text { bacteria }\end{array}}^{\text {Cross }} \begin{gathered}\begin{array}{c}\text { Acceptor } \\ \text { bacteria }\end{array} \\ \text { bacter }\end{gathered}$
bacteria $\left(\times 10^{-6} / \mathrm{ml}\right.$. $)$ in mixed culture at
$\%$ of acceptor-strain colonies found to be colicinogenic (and no. colicinogenic/ no. tested*) at

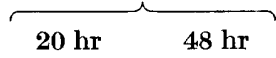

$140 \quad 95$

$71 \quad 42$

$130 \quad 89$

$62 \quad 46$

$130 \quad 66$

$37 \quad 33$

$160 \quad 150$

9378

\begin{tabular}{cc}
\hline $20 \mathrm{hr}$ & $48 \mathrm{hr}$ \\
$37(302 / 816)$ & $93(516 / 554)$ \\
$<0 \cdot 3(0 / 417)$ & $22(52 / 246)$ \\
$40(301 / 752)$ & $95(492 / 518)$ \\
$<0 \cdot 3(0 / 364)$ & $16(42 / 262)$ \\
$27(103 / 380)$ & $81(150 / 185)$ \\
$1 \cdot 4(3 / 216)$ & $4 \cdot 3(4 / 93)$ \\
$25(111 / 446)$ & $86(372 / 432)$ \\
$0 \cdot 8(2 / 258)$ & $1 \cdot 4(3 / 219)$
\end{tabular}

* Numbers in parentheses are: no. of acceptor-strain colonies found to be colicinogenic/no. of acceptor-strain colonies tested.

incubated at $37^{\circ}$ under aerobic conditions without agitation, disturbance or artificial aeration. Four crosses were made with the organisms in different combinations of phases: (1) donor Fim $+\mathbf{F} \times$ acceptor $\mathrm{Fim}^{+} \mathbf{F}$, (2) donor $\mathrm{Fim}^{+} \mathbf{F} \times$ acceptor $\mathrm{Fim}^{+} \mathbf{N}$, (3) donor $\mathrm{Fim}^{+} \mathbf{N} \times$ acceptor $\mathrm{Fim}^{+} \mathbf{F}$, (4) donor $\mathrm{Fim}^{+} \mathbf{N} \times$ acceptor $\mathrm{Fim}^{+} \mathbf{N}$. The results are shown in Table 3.

After $20 \mathrm{hr}$ incubation of the mixed culture, coll had been transmitted to a large 
percentage ( 37 and $40 \%$ ) of the acceptor bacteria in the crosses in which the acceptor culture was in the fimbriate phase; but it had not been transmitted even to a barely detectable proportion (about $\mathbf{0 . 3} \%$ ) of the acceptor bacteria in the crosses in which the acceptor culture was in the non-fimbriate phase. Similar results were obtained regardless of whether the donor culture was in the fimbriate or the non-fimbriate phase.

After $48 \mathrm{hr}$ incubation of the mixed culture the proportion of $\mathrm{Fim}^{+} \mathbf{F}$ acceptor bacteria that were colicinogenic had become still larger (93 and $95 \%$ ). By this time some of the $\mathrm{Fim}^{+} \mathrm{N}$ acceptors also had become colicinogenic, but the proportion $\left(22\right.$ and $16 \%$ ) was much less than that in the case of the $\mathrm{Fim}^{+} \mathrm{F}$ acceptors. The late acquisition of $\operatorname{colI}$ by the originally non-fimbriate $\left(\mathrm{Fim}^{+} \mathrm{N}\right)$ acceptor bacteria could possibly have been the result of the conversion of some of these bacteria to the fimbriate phase in the later stages of culture in broth. After $48 \mathrm{hr}$ a few of the cultures that originally were in the non-fimbriate phase showed a small degree of haemagglutinating activity and, therefore, must have contained a small proportion of fimbriate bacteria.

These results, indicating that the state of fimbriation of the acceptor bacteria, but not that of the donor bacteria is important in determining the frequency of transfer of coll, were confirmed in further experiments in which strain 1 lal as donor was crossed with $\mathrm{Fim}^{+} \mathbf{F}$ and $\mathrm{Fim}^{+} \mathbf{N}$ cultures of eleven strains of other serotypes as acceptors. The results of 10 of the 11 heterotypic crosses, 1 a $1 \times 2 a 19,2 \mathrm{~b} 1$, 3a106, 4a1, 4a2, 4b1, 5a4, 5a12, X105, Y3, were very similar to those of the homotypic crosses $(1 \mathrm{a} 1 \times 1 \mathrm{al})$; the results of the cross 1 a $1 \times 2$ a19 are shown in Table 3 . In crosses with the eleventh strain, $4 \mathrm{~b} 3$, as acceptor the results were completely negative. Neither the fimbriate nor the non-fimbriate form of strain $4 \mathrm{~b} 3$ acquired colI ; this strain seemed to be absolutely incompetent as an acceptor.

Two other Fim ${ }^{+}$strains, $2 \mathrm{bl}$ and $4 \mathrm{al}$, were investigated as donors. The acceptors were streptomycin-resistant mutants of the same strains and similar mutants of strains 1a1, 2a19, 3a106, 4a2, 5a12. The crosses gave similar results to those in which strain lal was donor.

\section{Transfer of colI from genotypically non-fimbriate $\left(\right.$ Fim $\left.^{-}\right)$ to genotypically fimbriate $\left(\mathrm{Fim}^{+}\right)$strains}

Crosses were tested between the Fim- strain $5 \mathrm{a} 3$ of Shigella flexneri as donor and fimbriate-phase $\left(\mathrm{Fim}^{+} \mathrm{F}\right)$ and non-fimbriate-phase $\left(\mathrm{Fim}^{+} \mathrm{N}\right)$ bacteria of twelve different $\mathrm{Fim}^{+}$strains as acceptors. The results are given in Table 4. Just as in the crosses with $\mathrm{Fim}^{+}$donors, the rate of transfer of coll from the $\mathrm{Fim}^{-}$donor was high when the acceptor bacteria were in the fimbriate phase and low when they were in the non-fimbriate phase. This finding was obtained with 11 of the 12 acceptor strains. The twelfth strain, $4 \mathrm{b3}$, proved to be absolutely incompetent as an acceptor, regardless of whether it was tested in the fimbriate or non-fimbriate phase.

Crosses were also made with the Fim ${ }^{-}$strains $2 \mathrm{al}$ and $4 \mathrm{c10}$ of Shigella flexneri and the Fim $^{-}$strain 2 of $S$. sonnei as donors. They gave similar results to those obtained with strain $5 \mathrm{a} 3$ as donor. 
Table 4. Transfer of colI from Shigella flexneri bacteria of Fim- strain 5 a3 as donors to fimbriate-phase $\left(\mathrm{Fim}^{+} \mathrm{F}\right)$ and non-fimbriate-phase $\left(\mathrm{Fim}^{+} \mathrm{N}\right)$ bacteria of 12 different $\mathrm{Fim}^{+}$strains as acceptors during growth in mixed culture for 20 or $48 \mathrm{hr}$

Crosses were made in $10 \mathrm{ml}$. broth inoculated with $10^{7}$ donor and $10^{7}$ acceptor bacteria and tested as described in Table 3 . In each cross and at each period of incubation, between 200 and 700 acceptor-strain colonies were tested for colicinogeny (only 50 colonies in culture with acceptor 1 al $\mathrm{Fim}^{+} \mathrm{N}$ at $20 \mathrm{hr}$.).

\begin{tabular}{|c|c|c|c|c|c|c|c|c|}
\hline \multirow{3}{*}{$\begin{array}{c}\text { Acceptor } \\
\text { strain }\end{array}$} & \multicolumn{4}{|c|}{$\begin{array}{l}\text { Viable count }\left(\times 10^{-6} / \mathrm{ml} .\right) \text { of the } \\
\text { acceptor-strain bacteria in the } \\
\text { culture in which they were }\end{array}$} & \multicolumn{4}{|c|}{$\begin{array}{l}\% \text { of acceptor-strain bacteria } \\
\text { found to be colicinogenic in the } \\
\text { culture in which they were }\end{array}$} \\
\hline & \multicolumn{2}{|c|}{$\mathrm{Fim}^{+} \mathbf{F}$} & \multicolumn{2}{|c|}{$\mathrm{Fim}^{+} \mathbf{N}$} & \multicolumn{2}{|c|}{$\mathrm{Fim}^{+} \mathbf{F}$} & \multicolumn{2}{|c|}{$\mathrm{Fim}^{+} \mathbf{N}$} \\
\hline & $20 \mathrm{hr}$ & $48 \mathrm{hr}$ & $20 \mathrm{hr}$ & $48 \mathrm{hr}$ & $20 \mathrm{hr}$ & $48 \mathrm{hr}$ & $20 \mathrm{hr}$ & $48 \mathrm{hr}$ \\
\hline 1a1 & 98 & 70 & 29 & 20 & 10 & 97 & $<\mathbf{2 . 0}$ & $2 \cdot 8$ \\
\hline $2 a 19$ & 110 & 80 & 64 & 51 & 14 & 57 & $<0.3$ & $1 \cdot 6$ \\
\hline 2b1 & 100 & 79 & 56 & 40 & 20 & 75 & $<0.3$ & 0.5 \\
\hline $3 a 106$ & 130 & 93 & 69 & 42 & 20 & 54 & $2 \cdot 7$ & $5 \cdot 6$ \\
\hline $4 a 1$ & 130 & 91 & 67 & 52 & 36 & 92 & $4 \cdot 3$ & $7 \cdot 0$ \\
\hline $4 a 2$ & 120 & 86 & 73 & 43 & 16 & 74 & 3.9 & $11 \cdot 4$ \\
\hline $4 \mathrm{bl}$ & 140 & 94 & 69 & 54 & 22 & 75 & $3 \cdot 0$ & $4 \cdot 2$ \\
\hline $4 \mathrm{~b} 3$ & 115 & 82 & 61 & 48 & $<0.2$ & $<0.3$ & $<0.3$ & $<0.4$ \\
\hline $5 a 4$ & 110 & 76 & 62 & 46 & 17 & 62 & $1 \cdot 3$ & $3 \cdot 1$ \\
\hline $5 a 12$ & 96 & 76 & 44 & 39 & 14 & 58 & $<0.5$ & 0.5 \\
\hline$\times 105$ & 130 & 92 & 68 & 47 & 19 & 54 & $2 \cdot 1$ & $9 \cdot 1$ \\
\hline Y3 & 125 & 88 & 71 & 49 & 16 & 44 & 1.2 & $5 \cdot 0$ \\
\hline
\end{tabular}

Table 5. Transfer of colI between different genotypically non-fimbriate strains of Shigella flexneri during growth in mixed culture for 20 or $48 \mathrm{hr}$

Crosses were made in $10 \mathrm{ml}$. broth inoculated with $10^{7}$ donor and $10^{7}$ acceptor bacteria and tested as described in Table 3 . The viable counts $\left(\times 10^{-6} / \mathrm{ml}\right.$.) of the acceptor-strain bacteria ranged between 25 and 120 in the different $20 \mathrm{hr}$ cultures, and between 22 and 78 in the $48 \mathrm{hr}$ cultures.

\begin{tabular}{|c|c|}
\hline \multicolumn{2}{|c|}{ Cross } \\
\hline $\begin{array}{l}\text { Donor } \\
\left(\text { Fim }^{-}\right) \\
\text {strain }\end{array}$ & $\begin{array}{c}\text { Acceptor } \\
\left(\text { Fim }^{-}\right) \\
\text {strain }\end{array}$ \\
\hline \multirow[t]{5}{*}{$2 a 1$} & 1b1 \\
\hline & $2 a 1$ \\
\hline & $3 \mathrm{c2}$ \\
\hline & $4 \mathrm{cl} 10$ \\
\hline & $5 \mathrm{a} 3$ \\
\hline \multirow[t]{5}{*}{$4 c 10$} & $1 \mathrm{bl}$ \\
\hline & $2 a 1$ \\
\hline & $3 \mathrm{c} 2$ \\
\hline & $4 \mathrm{c} 10$ \\
\hline & $5 \mathrm{a} 3$ \\
\hline \multirow[t]{5}{*}{$5 \mathrm{a3}$} & $1 \mathrm{bl}$ \\
\hline & $2 \mathrm{a} 1$ \\
\hline & $3 \mathrm{c} 2$ \\
\hline & $4 \mathrm{cl} 10$ \\
\hline & $5 a 3$ \\
\hline
\end{tabular}

\begin{tabular}{|c|c|}
\hline $20 \mathrm{hr}$ & $48 \mathrm{hr}$ \\
\hline$<0.9 \quad(0 / 122)$ & $<1 \cdot 1 \quad(0 / 86)$ \\
\hline $5 \cdot 2(26 / 502)$ & $6 \cdot 2(20 / 314)$ \\
\hline$<0.5 \quad(0 / 192)$ & $<0.7 \quad(0 / 143)$ \\
\hline $4 \cdot 6 \quad(6 / 128)$ & $13 \cdot 3(23 / 172)$ \\
\hline$<0.3 \quad(0 / 346)$ & $<0.3 \quad(0 / 317)$ \\
\hline$<1 \cdot 0 \quad(0 / 104)$ & $<1.2 \quad(0 / 82)$ \\
\hline $1 \cdot 4 \quad(5 / 354)$ & $2 \cdot 4(6 / 248)$ \\
\hline$<0.6 \quad(0 / 176)$ & $<1 \cdot 1 \quad(0 / 87)$ \\
\hline$<0.8 \quad(0 / 123)$ & $<1.1 \quad(0 / 92)$ \\
\hline$<0.3 \quad(0 / 326)$ & $<0.5 \quad(0 / 216)$ \\
\hline$<0.5 \quad(0 / 207)$ & $1 \cdot 6 \quad(2 / 124)$ \\
\hline $10 \cdot 7(42 / 392)$ & $21 \cdot 0(62 / 295)$ \\
\hline$<0.4 \quad(0 / 244)$ & $2.9 \quad(4 / 136)$ \\
\hline $10 \cdot 1(19 / 188)$ & $19 \cdot 1(25 / 131)$ \\
\hline $6 \cdot 2(17 / 274)$ & $13 \cdot 2(21 / 159)$ \\
\hline
\end{tabular}




\section{Transfer of coll to genotypically non-fimbriate $\left(\mathrm{Fim}^{-}\right)$strains as acceptors}

The results of crosses between strains that are Fim- in genotype, i.e. which never form fimbriae, are given in Table 5. Three streptomycin-sensitive Fim $^{-}$strains carrying colI were tested as donors and 5 streptomycin-resistant non-colicinogenic Fim $^{-}$strains as acceptors. After $48 \mathrm{hr}$ incubation of the mixed culture the proportion of acceptor bacteria that had acquired colI was, in most crosses, either small or undetectable. Nevertheless, it is noteworthy that some transfer of colI from Fimdonor to $\mathrm{Fim}^{-}$acceptor was detected in at least one cross with each of the 3 donors, and in at least one cross with each of the 5 acceptors. In 3 crosses with strain 5 a 3 as donor and in one with strain $2 \mathrm{al}$ as donor the percentage of colicinogenic acceptor bacteria was somewhat higher $\left(21,19,13\right.$ and $13 \%$ ) than in the other $\mathrm{Fim}^{-} \times \mathrm{Fim}^{-}$ crosses, but it was still not nearly as high as in comparable crosses with fimbriate acceptor bacteria (e.g. 44-97\%, Table 4 ).

Other crosses were made between $\mathbf{F i m}+\mathbf{F}$ bacteria of strain $1 \mathrm{al}$ as donors and the Fim $^{-}$strains $1 \mathrm{bl}, 2 \mathrm{a} 1,3 \mathrm{c} 2,4 \mathrm{c10}$ and $5 \mathrm{a} 3$ as acceptors. The percentage of colicinogenic acceptor bacteria at $48 \mathrm{hr}$ was never greater than 21 and in most crosses it was much less. These results confirm the relative incompetence of Fim- bacteria, as compared with $\mathrm{Fim}^{+} \mathbf{F}$ bacteria, as acceptors of colI, and also show that this incompetence applies when the donor bacteria are fimbriate as well as when they are non-fimbriate.

Table 6. Transfer of colI between donor and acceptor bacteria of Shigella flexneri Fim ${ }^{+}$ strain $1 a 1$ in mixed cultures inoculated with the donor and acceptor bacteria in different proportions

Tubes of $10 \mathrm{ml}$. broth were inoculated with the stated numbers (per tube) of donor bacteria in the fimbriate (F) phase and acceptor bacteria in the fimbriate (F) or nonfimbriate (N) phase, and were incubated for 20 or $48 \mathrm{hr}$; separate tubes were set up for each period of incubation. Between 532 and 628 acceptor-strain bacteria from each culture (tube) were tested for colicinogeny.

\begin{tabular}{|c|c|c|c|c|c|}
\hline \multicolumn{2}{|c|}{$\begin{array}{l}\text { Cross } \\
\text { Fimbrial phase and no. } \\
\text { of bacteria inoculated }\end{array}$} & \multicolumn{2}{|c|}{$\begin{array}{l}\text { Viable count }\left(\times 10^{-6} / \mathrm{ml} \text {.) }\right. \\
\text { of donor + acceptor bacteria } \\
\text { (and of acceptors only) at }\end{array}$} & \multicolumn{2}{|c|}{$\begin{array}{l}\% \text { of acceptor-strair } \\
\text { bacteria found to be } \\
\text { colicinogenic at }\end{array}$} \\
\hline $\begin{array}{c}\text { Donor } \\
\text { bacteria }\end{array}$ & $\begin{array}{c}\text { Acceptor } \\
\text { bacteria }\end{array}$ & $20 \mathrm{hr}$ & $48 \mathrm{hr}$ & $20 \mathrm{hr}$ & $48 \mathrm{hr}$ \\
\hline $\mathrm{F}, 10^{7}$ & $\mathrm{~F}, 10^{4}$ & $420(0 \cdot 37)$ & $380(0 \cdot 29)$ & 22 & 69 \\
\hline $\mathrm{F}, 10^{7}$ & $\mathrm{~N}, 10^{4}$ & $410(0 \cdot 16)$ & $370(0 \cdot 13)$ & $<0.2$ & 2.9 \\
\hline$F, 10^{4}$ & $\mathrm{~F}, 10^{7}$ & 390 & 330 & $0 \cdot 7$ & 34 \\
\hline$F, 10^{4}$ & $\mathrm{~N}, 10^{7}$ & 380 & 320 & $<0.2$ & $<0.2$ \\
\hline
\end{tabular}

Influence of the relative numbers of the donor and acceptor bacteria in the mixed culture

In the experiments (e.g. see Tables 3,4) in which $\mathrm{Fim}^{+} \mathbf{F}$ and $\mathrm{Fim}^{+} \mathbf{N}$ bacteria of the same strain were compared as acceptors of coll in crosses with the same donor culture, the viable count of the acceptor-strain bacteria in the mixed culture after 20 or $48 \mathrm{hr}$ was 2-3 times greater when the acceptors were $\mathbf{F i m}+\mathbf{F}$ than when they were Fim ${ }^{+}$N. This finding agrees with the observations of Duguid \& Gillies (1957) and Duguid \& Wilkinson (1961) that fimbriate bacteria grow to higher concentra- 
tions in aerobic static broth than do non-fimbriate bacteria; they do this apparently as a result of their ability to grow as a pellicle on the surface of the broth where they have free access to atmospheric oxygen. The question therefore arises as to whether the infrequency of transfer of colI to non-fimbriate acceptor bacteria was due to the growth and metabolism of these acceptor bacteria being depressed in the post-logarithmic phase of culture through their being overgrown by the fimbriate donor bacteria. This explanation is not supported by the results of mixed-culture experiments in which donor and acceptor bacteria of strain la1 were inoculated into broth in different proportions (Table 6). The relative numbers of the donor and acceptor bacteria did not have a very great influence on the frequency of transfer of colI. Indeed, in a cross in which non-fimbriate $\left(\mathrm{Fim}^{+} \mathrm{N}\right)$ acceptor bacteria in the inoculum outnumbered fimbriate $\left(\mathrm{Fim}^{+} \mathrm{F}\right)$ donor bacteria by 1000 to $1\left(\mathrm{~F}, 10^{4} ; \mathrm{N}, 10^{7}\right)$, no transfer of colI was detected at $48 \mathrm{hr}$.

\section{Transfer of colI-P9 from Salmonella typhimurium to Shigella flexneri}

Ozeki et al. (1962) showed that when Salmonella typhimurium strain LT2 cysD-36 carrying colI $-P 9$ was grown overnight in mixed culture in broth with a non-colicinogenic line of the same strain, about $50 \%$ of the latter bacteria acquired colI-P 9 . We made tests with strain LT 2 cys $D-36$ colI $-P$ 9, which is $\mathrm{Fim}^{+}$, to determine whether it was as efficient in donating colI-P9 to Shigella flexneri as it was to $S$. typhimurium, and whether the frequency of transfer of colI-P9 was influenced by the state of fimbriation of the acceptor bacilli in the same way as was the transfer of colI from $S$. flexneri donors. $S$. typhimurium LT 2 cysD-36 colI-P9 was crossed with $5 \mathrm{Fim}^{-}$and $12 \mathrm{Fim}^{+}$strains of $S$. flexneri as acceptors; the $\mathrm{Fim}^{+}$acceptors were tested both in the fimbriate and the non-fimbriate phase. Mixed cultures were grown in $10 \mathrm{ml}$. broth from inocula of $10^{7}$ donor and $10^{7}$ acceptor bacteria. The proportions of acceptor-strain bacteria found to be colicinogenic after 20 and $48 \mathrm{hr}$ were invariably low in the crosses with $\mathrm{Fim}^{-}$acceptors (under $2.5 \%$ ) and $\mathrm{Fim}^{+} \mathrm{N}$ acceptors (under $7 \%$ ), but were high (e.g. $40 \%$ ) in those with Fim $^{+} \mathbf{F}$ acceptors. These results of crosses with the $S$. typhimurium donor were very similar to the results of the crosses with $S$. flexneri donors. A minor difference was that in the crosses with $S$. typhimurium the proportion of colicinogenic acceptor bacteria did not continue to increase when incubation of the mixed culture was prolonged from 20 to $48 \mathrm{hr}$, but instead became somewhat smaller again. The absence of continued transfer between 20 and $48 \mathrm{hr}$ may have been due to the fact that the $S$. flexneri acceptor bacteria became very much overgrown by the $S$. typhimurium donor bacteria. At $48 \mathrm{hr}$ the viable counts $\left(\times 10^{6}\right) / \mathrm{ml}$. in the mixed culture were: $S$. typhimurium 570 and $S$. flexneri $5 \cdot 7$ when $S$. flexneri was $\mathrm{Fim}^{+} \mathrm{F}$, and $S$. typhimurium 570 and $S$. flexneri $2 \cdot 6$ when $S$. flexneri was $\mathrm{Fim}^{+} \mathbf{N}$.

\section{Kinetics of transfer of colI}

The frequency of transfer of colI was observed after different periods of incubation from 2 to $72 \mathrm{hr}$ in crosses between $\mathrm{Fim}^{+} \mathrm{F}$ bacilli of Shigella flexneri strain 1al as donors and Fim $+F$ bacteria of $S$. flexneri strains 1 al and 2 a19 as acceptors. A separate tube of mixed broth culture was set up for examination after each period of incubation and about 500 acceptor-strain colonies in platings from each culture were 
examined for colicinogeny. The results of the experiment with strain 1al as acceptor are given in Table 7; almost identical results were obtained in a similar experiment with strain 2 a19.

No transfer of coll was detected after the first $2 \mathrm{hr}$ of incubation, but after $4 \mathrm{hr}$ a small proportion $(0 \cdot 3 \%)$ of acceptor bacteria possessed colI and the proportion of acceptors with colI increased slowly up to $12 \mathrm{hr}(4 \%)$ and then more rapidly up to $24 \mathrm{hr}(30 \%)$. By $48 \mathrm{hr}$, almost all $(97 \%)$ of the acceptor bacteria were colicinogenic. The transfer of colI thus took place mainly in the period of slow post-logarithmic growth, which began after the first $6 \mathrm{hr}$ of incubation. Most transfers took place after the 12th hr, by which time a pellicle had developed on the surface of the culture.

Table 7. Kinetics of transfer of colI between fimbriate-phase donor and acceptor bacteria of Shigella flexneri strain 1a1 during growth in mixed culture at $37^{\circ}$

Nine tubes of $10 \mathrm{ml}$. broth were each inoculated with $10^{7} \mathrm{Fim}^{+} \mathrm{F}$ donor bacteria and $10^{7} \mathrm{Fim}^{+\mathrm{F}}$ acceptor bacteria and incubated under aerobic static conditions at $37^{\circ}$ for different periods up to $\mathbf{7 2} \mathrm{hr}$. After incubation, the culture was homogenized and tested for the viable count of acceptor-strain bacteria and the proportion of acceptor-strain bacteria which were colicinogenic. A separate tube of mixed culture was used for each period of incubation so that it and any pellicle it formed were undisturbed until the time of testing.

$\begin{array}{cc}\begin{array}{c}\text { Period of incubation } \\ \text { of mixed culture } \\ \text { (hr) }\end{array} & \begin{array}{c}\text { Viable count of } \\ \text { acceptor-strain } \\ \text { bacteria }\left(\times 10^{-6} / \mathrm{ml} .\right)\end{array} \\ 0 & 1 \cdot 0 \\ 2 & 5 \cdot 6 \\ 4 & 68 \\ 6 & 130 \\ 8 & 180 \\ 10 & 190 \\ 12 & 190 \\ 24 & 180 \\ 48 & 120 \\ 72 & 89\end{array}$

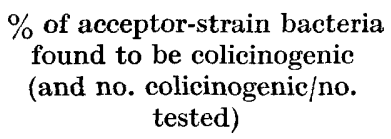

There seem to be two possible explanations for the very low frequency of transfer of coll in the early hours of incubation of the mixed cultures. (1) The initial concentration of the inoculated bacteria (donors and acceptors each about $10^{6} / \mathrm{ml}$.) may have been so low that collisions and contacts between bacteria, and thus opportunities for transfer of colI, were rare until the numbers of bacteria had increased as a result of several hours' growth. Against this explanation, however, should be noted the fact that transfer was still relatively infrequent throughout the period between the 4th and 12th hours of incubation, i.e. in a period when the number of viable bacteria was nearly maximal. A possible reason for the finding that the majority of transfers took place after $12 \mathrm{hr}$ is that the best opportunities for contact and transfer of colI between bacteria existed in the pellicle of bacteria which developed on the surface of the broth after about the 10th hour of incubation and in which most of the slow post-logarithmic growth of bacteria presumably took place.

(2) Only a small proportion of the bacteria of the donor cultures may have been competent to transmit the colI factor. Ozeki et al. (1962) found that the low fre- 
quency of transfer of $\operatorname{colI}-\boldsymbol{P} 9$ during the first $6 \mathrm{hr}$ of incubation of mixed cultures of donor and acceptor stocks of Salmonella typhimurium $\mathrm{LT} 2 \mathrm{cysD-36}$ was due to the fact that only about $0.02 \%$ of the bacteria in the donor cultures were competent to transmit the colI-P9 factor. They explained the high rate of transfer after prolonged $(20 \mathrm{hr})$ incubation as being the result of an 'epidemic' spread of colI-P9 which took place through the acceptor population during the period of slow postlogarithmic growth. Apparently a large proportion of the freshly infected acceptor bacteria become competent donors, able to conjugate with other acceptor bacteria and pass colI-P9 into them. Stocker et al. (1963) showed that $50 \%$ of the S. typhimurium bacteria which had freshly acquired colI-P9 became competent donors and were able to pass the factor into acceptor bacteria with high frequency. Preparations with a high proportion of competent donor bacteria were named HFC preparations (high-frequency colicinogeny-transferring); when mixed with acceptor bacteria at concentrations of more than $10^{8}$ bacteria/ml., they transmitted coll-P9 to about $50 \%$ of the acceptor bacteria in $1 \mathrm{hr}$.

\section{Attempt to prepare an HFC culture of Shigella flexneri}

The technique of Stocker et al. (1963) was used. About $5 \times 10^{5} \mathrm{Fim}+\mathrm{F}$ bacteria of streptomycin-sensitive Shigella flexneri strain 1 al carrying colI or colI-P9 as original donors and about $10^{7} \mathrm{Fim}^{+} \mathbf{F}$ non-colicinogenic streptomycin-sensitive la1 bacteria as intermediate donors were inoculated into $10 \mathrm{ml}$. broth and the mixed culture incubated for $18 \mathrm{hr}$. The culture was then diluted tenfold with fresh broth and incubated for a further $2 \mathrm{hr}$. After the first $18 \mathrm{hr}$ of incubation the proportion of colicinogenic bacteria was, in different experiments, between 17 and $33 \%$, and after dilution and secondary incubation for $2 \mathrm{hr}$ it was only about half as much (9-21\%). These values are much lower than those obtained by Stocker et al. with Salmonella typhimurium, namely 30-70\% after the first $18 \mathrm{hr}$ and 50-90\% after secondary $2 \mathrm{hr}$ incubation. Thus $\boldsymbol{S}$. flexneri did not behave in the same manner as $S$. typhimurium and our attempt to prepare an HFC culture was not pursued. A possible reason for the different behaviour of $S$. flexneri may lie in its non-motility, since Stocker et al. found that motility was important in the development of HFC preparations of $\boldsymbol{S}$. typhimurium. They found that when the intermediate (non-colicinogenic) strain was non-motile, the proportion of the bacteria that acquired colicinogeny after primary incubation for $18 \mathrm{hr}$ and secondary incubation for $2 \mathrm{hr}$ was less than $1 \%$, whereas when the intermediate strain was motile the proportion was about $70 \%$.

\section{'Epidemic' spread of colI within the acceptor population}

Although we failed to demonstrate by the production of an HFC culture that Shigella flexneri organisms which have been freshly infected with colI are more effective in transmitting colI than the bacteria of a long-established colicinogenic culture, it still seemed possible that such bacteria, like comparable Salmonella typhimurium organisms, may be exceptionally competent as donors. If they are specially competent, then it is likely that the majority of the acceptor bacteria that become colicinogenic during $48 \mathrm{hr}$ in a mixed culture do so as a result of the colI factor spreading 'epidemically' from one acceptor bacterium to another, and not by acquiring the factor directly from the bacteria of the donor strain. An experiment 
was made to determine whether such an 'epidemic' spread of colI took place within the acceptor population. The method of the experiment involved adding streptomycin ( $1 \mathrm{mg} . / \mathrm{ml}$.), to a mixed culture to kill the streptomycin-sensitive donor bacteria after the culture had been incubated for only $8 \mathrm{hr}$ and when only a few bacteria of the streptomycin-resistant acceptor strain had acquired colI ; the culture was then re-incubated for the remainder of a period of $20 \mathrm{or} 48 \mathrm{hr}$. It was found that the proportion of acceptor bacteria possessing coll increased very greatly during the secondary incubation and, since all the donor strain bacteria were then dead, the increase must have been the result of an 'epidemic' spread of coll taking place through the population of acceptor-strain bacteria.

Table 8. Transfer of colI between donor and acceptor Shigella flexneri organisms grown in mixed cultures with and without the addition of streptomycin after the first $8 \mathrm{hr}$

For each cross, 4 tubes of $10 \mathrm{ml}$. broth were inoculated with $10^{6}$ streptomycinsensitive donor bacteria and $10^{7}$ streptomycin-resistant acceptor bacteria per tube. After incubation at $37^{\circ}$ for $8 \mathrm{hr}$, each culture was mixed until homogeneous and samples were taken from it for estimation of the viable count of acceptor-strain bacteria and the proportion that were colicinogenic. Streptomycin $(1 \mathrm{mg} . / \mathrm{ml}$.) was added to two of the cultures and all four were then reincubated. A streptomycin-treated and an untreated culture were examined after a total of $20 \mathrm{hr}$ incubation and the other two cultures at $48 \mathrm{hr}$.

\begin{tabular}{|c|c|c|}
\hline \multicolumn{2}{|c|}{ Cross } & \multirow[b]{2}{*}{$\begin{array}{l}\text { Treatment } \\
\text { at } 8 \mathrm{hr}\end{array}$} \\
\hline $\begin{array}{c}\text { Donor } \\
\text { bacteria }\end{array}$ & $\begin{array}{l}\text { Acceptor } \\
\text { bacteria }\end{array}$ & \\
\hline 1 a1 $\mathrm{Fim}^{+} \mathrm{F}$ & lal $\mathrm{Fim}^{+\mathrm{F}}$ & $\begin{array}{l}\text { Untreated } \\
\text { Streptomycin }\end{array}$ \\
\hline 1 a1 $\mathrm{Fim}^{+} \mathrm{F}$ & 2a1 $\mathrm{Fim}^{-}$ & $\begin{array}{l}\text { Untreated } \\
\text { Streptomycin }\end{array}$ \\
\hline $5 \mathrm{a3} \mathrm{Fim}^{-}$ & 1 al $\mathrm{Fim}^{+\mathrm{F}}$ & $\begin{array}{l}\text { Untreated } \\
\text { Streptomycin }\end{array}$ \\
\hline
\end{tabular}

\begin{tabular}{|c|c|c|c|c|c|}
\hline \multicolumn{3}{|c|}{$\begin{array}{l}\text { Viable count } \\
\left(\times 10^{-6} / \mathrm{ml} .\right) \text { of } \\
\text { acceptor-strain } \\
\text { bacteria at }\end{array}$} & \multicolumn{3}{|c|}{$\begin{array}{l}\% \text { of acceptor- } \\
\text { strain bacteria } \\
\text { found to be } \\
\text { colicinogenic at }\end{array}$} \\
\hline $\mathrm{hr} *$ & $20 \mathrm{hr}$ & $48 \mathrm{hr}$ & $8 \mathrm{hr} \dagger$ & $20 \mathrm{hr} 4$ & $48 \mathrm{hr}$ \\
\hline 320 & 360 & 340 & 0.44 & 30 & 76 \\
\hline 320 & 355 & 345 & $0 \cdot 4: 5$ & 0.37 & 62 \\
\hline 290 & 305 & 215 & $0 \cdot 28$ & 12 & 24 \\
\hline 290 & 310 & 220 & $0 \cdot 29$ & $0 \cdot 24$ & 0.47 \\
\hline 335 & 345 & 335 & $0 \cdot 69$ & 37 & 87 \\
\hline 335 & $\mathbf{3 4 0}$ & 260 & $0 \cdot 34$ & $1 \cdot 8$ & 69 \\
\hline
\end{tabular}

* Results are averages for the four tubes of the cross. $\dagger$ Results are averages for the two tubes that were later examined at 20 and $48 \mathrm{hr}$.

Table 8 shows the results of experiments made in this way on three crosses of Shigella flexneri strains: (1) donor $\mathbf{F i m}^{+} \mathbf{F} \times$ acceptor $\mathbf{F i m}^{+} \mathbf{F}$, (2) donor $\mathbf{F i m}^{+} \mathbf{F} \times$ acceptor Fim-; (3) donor Fim- $\times$ acceptor Fim ${ }^{+}$F. In each of the crosses a small proportion $(0 \cdot 28-0 \cdot 69 \%)$ of the acceptor bacteria had acquired coll by the end of the first $8 \mathrm{hr}$ of incubation. In the cultures with $\mathrm{Fim}^{+} \mathrm{F}$ acceptors that were treated with streptomycin at $8 \mathrm{hr}$ and then reincubated until $48 \mathrm{hr}$, the proportion of acceptor bacteria possessing coll rose to values (62 and $69 \%$ ) nearly as high as those $(76$ and $87 \%$ ) in the control cultures without streptomycin. On the other hand, the proportion of colicinogenic acceptor bacteria remained very low (under $0.5 \%$ ) in the streptomycin-treated cultures in which the acceptor was Fim-. Thus it appeared that colI spread epidemically through the population of acceptor bacteria when these were fimbriate $\left(\mathrm{Fim}^{+} \mathbf{F}\right)$, but did not do so when they were non-fimbriate $\left(\mathrm{Fim}^{-}\right)$. The continuing acquisition of $\mathrm{colI}$ by $\mathrm{Fim}^{+} \mathbf{F}$ acceptor bacteria after the donor-strain bacteria had been killed with streptomycin must have been due to an epidemic 
spread of colI that originated from the few acceptor bacteria that had acquired coll from the donor-strain bacteria before the addition of streptomycin. It may be assumed that the acceptor bacteria did not acquire colI from the killed donor bacteria, since it was found that when streptomycin was added at $2 \mathrm{hr}$ instead of $8 \mathrm{hr}$, i.e. before any acceptor bacteria had become colicinogenic, none of the acceptor bacteria became colicinogenic during secondary incubation for $48 \mathrm{hr}$.

An interesting difference in the results between the streptomycin-treated and the untreated crosses with $\mathrm{Fim}^{+} \mathrm{F}$ acceptors (Table 8 ) is seen in the finding that in the streptomycin-treated cultures the increase in the proportion of colicinogenic acceptor bacteria was delayed until after the 20th hour of incubation, whereas in the untreated cultures it was already very great at $20 \mathrm{hr}$ (compare 0.37 with $30 \%$ ). This finding seems to indicate that in the untreated cultures the large increase in colicinogenic acceptors that took place between 8 and $20 \mathrm{hr}$ was mainly due to transfer of colI from the donor-strain bacteria to the acceptor-strain bacteria, and not to epidemic spread among the acceptors. It may perhaps also be concluded that the proportion of the donor-strain bacteria in the culture at $8 \mathrm{hr}$ that were 'competent donors' of colI was at least much greater than about $0.5 \%$, which was the proportion of the tenfold larger population of acceptor bacteria that by $8 \mathrm{hr}$ had become colicinogenic. In contrast, Ozeki et al. (1962) found that only about $0.02 \%$ of the bacteria in an established colicinogenic stock of Salmonella typhimurium strain LT 2 were 'competent donors'. However, these various conclusion are valid only on the assumption that the streptomycin added to our cultures had no effect other than that of killing the donor-strain bacteria.

Control tests indicated that the increase of colicinogenic bacteria in the streptomycin-treated cultures was not due to the emergence, survival and multiplication of streptomycin-resistant mutants of the colicinogenic donor strain. The rates of mutation of strains $1 \mathrm{la} 1$ and $\mathbf{5 a} 3$ to resistance to $1 \mathrm{mg}$. streptomycin $/ \mathrm{ml}$. are very low, less than 1 per $10^{11}$ bacteria, and the number of viable donor-strain bacteria in the mixed cultures at $8 \mathrm{hr}$ cannot have exceeded about $10^{9} / 10 \mathrm{ml}$. tube. Fifty pure cultures of the donor strain $1 \mathrm{al}$ and 50 of the donor strain $5 \mathrm{a} 3$ were grown for $8 \mathrm{hr}$ in tubes of $10 \mathrm{ml}$. broth inoculated with about $10^{6}$ bacteria; streptomycin was then added and incubation continued until $48 \mathrm{hr}$. None of these control cultures yielded a growth of streptomycin-resistant mutants. Serological agglutination tests were made on $\mathbf{4 0 0}$ streptomycin-resistant colicinogenic colonies obtained in platings grown from the streptomycin-treated mixed cultures of $5 \mathrm{a} 3$ donor and $1 \mathrm{a} 1$ acceptor bacteria after they had been incubated for 20 and $48 \mathrm{hr}$ (Table 8) and on another 400 such colonies from the corresponding cultures grown without the addition of streptomycin; all 800 colonies were found to be of the acceptor (1a) serotype. This finding confirms that the streptomycin-resistant colicinogenic organisms were not donor strain (5a) bacteria which had acquired resistance to streptomycin either by spontaneous mutation or by transfer of a resistance factor from the acceptor bacteria.

\section{Pellicle formation and the transmission of colI}

In cultures of Shigella flexneri in aerobic static broth the development of fimbriae is associated with the formation on the surface of the broth of a thin pellicle composed of aggregated bacteria. In cultures inoculated with fimbriate-phase organisms, e.g. Fim $+\mathrm{F}$ lal bacteria, the pellicle appears after about $10 \mathrm{hr}$ of incubation 
(Duguid \& Wilkinson, 1961). Since, in our crosses with Fim $+\mathrm{F}$ acceptors, the main increase in the proportion of colicinogenic acceptor bacteria took place only in the period of incubation after the first 10-12 hr (e.g. see Table 7), it seemed possible that the conjugation of bacteria and the transfer of colI were effected principally in the pellicle. To investigate this possibility the following experiment was done.

A tube of $10 \mathrm{ml}$. broth was inoculated with $10^{7} \mathrm{Fim}+\mathrm{F}$ donor bacteria and $10^{7}$ $\mathrm{Fim}^{+} \mathrm{F}$ acceptor bacteria and incubated under aerobic static conditions for $8 \mathrm{hr}$. The culture was then homogenized and examined for colicinogenic acceptor bacteria; the proportion of these was found to be about $1 \%$. The culture then was re-incubated for $12 \mathrm{hr}$, but during this second period of incubation it was gently agitated at intervals of $1 \mathrm{hr}$. The intermittent agitation was sufficient to prevent the formation of a surface pellicle, but it could not have effectively aerated the culture or have interfered mechanically with the conjugation of bacteria, since the culture was static for the greater part of the $12 \mathrm{hr}$ period. After the total of $20 \mathrm{hr}$ of incubation, the proportion of colicinogenic acceptor bacteria was found to have increased only to $7 \%$. By contrast, the proportion in an unagitated control culture increased from $1 \%$ at $8 \mathrm{hr}$ to $34 \%$ at $20 \mathrm{hr}$. Both the agitated and control cultures showed strong haemagglutinating activity, indicating that they were richly fimbriate. When the agitated culture was left undisturbed for a further $28 \mathrm{hr}$ at $37^{\circ}$, a surface pellicle appeared and the proportion of colicinogenic acceptor bacteria increased to $95 \%$. These findings seem to indicate that the formation of a surface pellicle facilitates the transmission of $\operatorname{coll}$.

\section{Influence of aeration of the mixed culture on the transfer of colI}

When broth cultures ( $2 \mathrm{ml}$. broth in a $20 \mathrm{ml}$. bottle) inoculated with $\mathrm{Fim}^{+} \mathbf{F}$ donor and $\mathrm{Fim}^{+} \mathrm{F}$ acceptor bacteria of strain $1 \mathrm{lal}$ were agitated continuously in a rotating machine while being incubated for $20 \mathrm{hr}$, the proportion of colicinogenic acceptor bacteria did not increase above $2 \%$. The cultures did not form a pellicle, although they were moderately richly fimbriate. The poor transfer of coll may, as in the previous experiment, have been due to to the effect of agitation in preventing pellicle formation. However, an additional factor may have played a part in this experiment in which agitation was continuous and aeration therefore efficient. In the continuously aerated culture, the growth proceeds rapidly and gives a maximum yield of bacteria within about $6 \mathrm{hr}$. After this time it ceases abruptly, probably as a result of exhaustion of the oxidizable energy-yielding nutrients in the medium. Ozeki et al. (1962), who found that transfer of colI-P 9 in mixed cultures of Salmonella typhimurium grown in aerobic static broth took place mainly during the prolonged phase of slow post-logarithmic growth, and that aeration by continuous shaking prevented transfer of the colI factor, considered that the inhibition produced by aeration might be due to the effect of aeration in eliminating the phase of postlogarithmic growth.

\section{Transfer of colI in mixtures of separately grown cultures of donor and acceptor strains}

In all the experiments described above the mixed cultures were grown from relatively small inocula, e.g. about $10^{7}$ donor and $10^{7}$ acceptor bacteria, and this procedure allowed the bacteria to pass through a substantial period of rapid logarithmic 
growth. Other experiments were made under different conditions. The donor and acceptor strains were first grown separately for $24 \mathrm{hr}$ in tubes of aerobic static broth. These post-logarithmic cultures, which contained $1-4 \times 10^{8}$ viable bacteria/ ml., were mixed together in a tube, $5 \mathrm{ml}$. with $5 \mathrm{ml}$., and the mixture was incubated for a period of 8,20 or $48 \mathrm{hr}$ without the addition of any fresh broth. This procedure caused the donor and acceptor bacteria to be mixed in high concentrations from the outset and it permitted only a slow and limited growth in the mixture; the total count (turbidity) increased about twofold in $48 \mathrm{hr}$.

Table 9. Transfer of coll between $24 \mathrm{hr}$ fimbriate-phase $(F)$ and non-fimbriate-phase $(N)$ broth cultures of Shigella flexneri strain 1a1 after mixture and incubation without the addition of fresh broth

For each cross, $\mathbf{3}$ tubes were set up containing a homogeneous mixture of $5 \mathrm{ml}$. of a $24 \mathrm{hr}$ broth culture of the donor bacteria and $5 \mathrm{ml}$. of a $24 \mathrm{hr}$ broth culture of the acceptor bacteria. The mixtures were incubated under aerobic static conditions at $37^{\circ}$ for 8,20 or $48 \mathrm{hr}$ before harvesting and testing.

\begin{tabular}{|c|c|c|c|c|}
\hline \multicolumn{2}{|c|}{$\overbrace{\text { Donor Acceptor }}^{\text {Cross }}$} & \multicolumn{3}{|c|}{$\begin{array}{c}\text { Viable count } \\
\left(\times 10^{-6} / \mathrm{ml} .\right) \text { of } \\
\text { acceptor-strain } \\
\text { bacteria at }\end{array}$} \\
\hline phase & phase & $8 \mathrm{hr}$ & $20 \mathrm{hr}$ & $48 \mathrm{hr}$ \\
\hline$F^{\prime}$ & $\mathbf{F}$ & 120 & 100 & 75 \\
\hline $\mathbf{F}$ & $\mathbf{N}$ & 51 & 42 & 31 \\
\hline $\mathbf{N}$ & $\mathbf{F}$ & 140 & 120 & 100 \\
\hline $\mathbf{N}$ & $\mathbf{N}$ & 54 & 38 & 32 \\
\hline
\end{tabular}

\begin{tabular}{rcc}
$\begin{array}{l}\text { \% of acceptor-strain bacteria } \\
\text { found to be colicinogenic at }\end{array}$ \\
\hline $\begin{array}{r}8 \mathrm{hr} \\
\mathbf{2 0} \mathrm{hr}\end{array}$ & $48 \mathrm{hr}$ \\
$\mathbf{1 . 2}$ & 66 & 91 \\
0.4 & $<0.4$ & 22 \\
0.9 & 50 & 92 \\
$<0.3$ & $<0.5$ & 4.8
\end{tabular}

Table 9 shows the results of crosses between $\mathbf{F i m}+\mathbf{F}$ and $\mathbf{F i m}+\mathbf{N}$ cultures of Shigella flexneri strain 1a1. Separate tubes of each mixture were put up for examination after 8,20 and $48 \mathrm{hr}$. There was little transfer of coll during the first $8 \mathrm{hr}$ after mixing, although throughout this period the donor and acceptor bacteria were exposed to each other in high concentrations and under conditions favourable to slow post-logarithmic growth. A few colicinogenic acceptor bacteria were found at $8 \mathrm{hr}$ in the mixtures in which the acceptors were in the fimbriate phase, but the proportion of these bacteria (about $1 \%$ ) was no higher than it was in comparable cultures grown for $8 \mathrm{hr}$ from small inocula. The delay in transfer of colI may have been due to the time taken for re-establishment of a surface pellicle after the mixing of the cultures.

In the crosses in which the acceptor was $\mathrm{Fim}^{+} \mathrm{F}$ the proportion of colicinogenic acceptor bacteria increased sharply after the first $8 \mathrm{hr}$ and reached fairly high values $(50$ and $66 \%$ ) at $20 \mathrm{hr}$, and very high values (91 and $92 \%$ ) at $48 \mathrm{hr}$. The crosses in which the acceptor was $\mathrm{Fim}^{+} \mathbf{N}$ did not yield colicinogenic acceptor bacilli until $48 \mathrm{hr}$ and then did so only in a proportion much lower $(4 \cdot 8$ and $22 \%)$ than that in the crosses with $\mathrm{Fim}^{+} \mathrm{F}$ acceptors. These results are very like the results obtained for mixed cultures grown from small inocula.

When the donor and acceptor cultures were grown for several (up to 7) days before they were mixed, the proportions of colicinogenic acceptors after 20 and $48 \mathrm{hr}$ of incubation of the mixture were almost as high as those in the mixtures of $24 \mathrm{hr}$ cultures. When, however, the parent cultures were still older the rate of transfer of 
coll was decreased. Thus, in a cross of donor $5 \mathrm{a} 3 \mathrm{Fim}^{-}$with acceptor $1 \mathrm{al} \mathrm{Fim}^{+} \mathbf{F}$, the percentages of colicinogenic acceptor bacteria at 20 and 48 hrwere 36 and 97 when the age of the parent cultures before mixture was $24 \mathrm{hr}, 75$ and 98 when the age was $48 \mathrm{hr}, 36$ and 95 when it was 5 days, 20 and 76 when it was 10 days, 1 and 27 when it was 15 days, and $<0.2$ and 8 when it was 20 days. The diminishing rate of transfer in the mixtures of the older cultures may have been due to the diminishing viability of the bacteria in them.

In the experiments just described, the parent cultures and the mixture of them were incubated under aerobic static conditions, which permitted them to form a pellicle and undergo a prolonged phase of slow post-logarithmic growth. When,

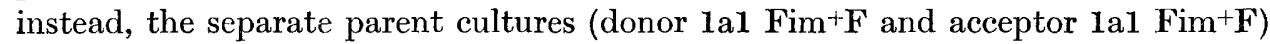
were grown for $24 \mathrm{hr}$ with continuous agitation and aeration, no detectable transfer of colI took place when the mixture was incubated under aerobic static conditions for $48 \mathrm{hr}$. Ozeki et al. (1962) obtained a similar result with aerated cultures of Salmonella typhimurium and they attributed the absence of transmission to the energy sources in the medium being exhausted before the cultures were mixed.

\section{Transfer of colI in defined medium}

A high rate of transmission of coll was demonstrated in mixed cultures of donor 5 a3 $\mathrm{Fim}^{-}$and acceptor 1 al $\mathrm{Fim}^{+} \mathrm{F}$ bacteria grown in liquid glucose ammonium salts medium supplemented with nicotinic acid. Strain 1al formed a delicate pellicle on the surface of this medium and the culture gave a positive haemagglutination reaction, indicating that it was fimbriate. Separate cultures of the donor and acceptor bacteria were grown in the defined medium to provide the inocula for the mixed cultures. The mixed cultures, which were inoculated with $10^{7}$ donor and $10^{7}$ acceptor bacteria, were grown in $10 \mathrm{ml}$. defined medium under aerobic static conditions for $48 \mathrm{hr}$. At the end of this period, in different experiments, between 37 and $\mathbf{5 8} \%$ of the acceptor bacteria were colicinogenic. When the bacteria from donor and acceptor cultures which had been grown for $48 \mathrm{hr}$ in defined medium were washed twice in saline, resuspended in equal proportion and to their original concentration in fresh defined medium, and then incubated for another $48 \mathrm{hr}$, the proportion of the acceptor bacteria, that became colicinogenic ranged from 46 to $74 \%$. When such mixtures of washed donor and acceptor bacteria ( $>10^{8}$ viable bacteria $/ \mathrm{ml}$.) were incubated in defined medium that lacked either glucose or nicotinic acid, both of which were essential for growth, there was little or no transfer of colI $(<1 \%)$.

\section{DISCUSSION}

The colicinogenic factor colI was found to be transmitted between the bacteria of different strains and serotypes of Shigella flexneri when these bacteria were grown together in mixed culture in aerobic static broth for 20 or $48 \mathrm{hr}$ at $37^{\circ}$. Transmission, though at a low rate, was observed in crosses in which both the donor and acceptor organisms were genotypically non-fimbriate (Fim-) and it is therefore clear that the presence of fimbriae is not essential for transmission. By 'fimbriae', in this context, we mean the ordinarily numerous kind of non-flagellar filaments that are easily demonstrable by electron microscopy and haemagglutination tests. Scanty 'F fimbriae' ('F pili') of the kind demonstrated by Crawford \& Gesteland (1964) 
and Brinton, Gemski \& Carnahan (1964) in Escherichia coli and thought by the latter authors to serve as an organ of conjugation in enterobacteria, would not have been detected by us if they had been present in the strains of $S$. flexneri that we have designated Fim $^{-}$.

A high rate of transmission of coll was obtained only in those crosses in which the acceptor Shigella flexneri organisms were both genotypically and phenotypically fimbriate $(\mathbf{F i m}+\mathbf{F})$. Under these conditions, and regardless of whether the donor organisms were fimbriate or non-fimbriate, usually between 50 and $95 \%$ of the acceptor bacteria became colicinogenic during growth for $48 \mathrm{hr}$ in mixed culture. When the acceptor bacteria were either genotypically non-fimbriate (Fim $\left.{ }^{-}\right)$or genotypically fimbriate but in the non-fimbriate phase $\left(\mathrm{Fim}^{+} \mathbf{N}\right)$, the proportion of them which became colicinogenic was usually only between 0.2 and $20 \%$. The expression of fimbriation in the acceptor bacteria thus had the effect of promoting a high rate of transmission, whereas the state of fimbriation in the donor bacteria was without effect.

In many respects the conditions and course of transmission of coll observed in our experiments with fimbriate Shigella flexneri organisms resembled those observed by Ozeki et al. (1962) and Stocker et al. (1963) in similar experiments with the fimbriate strain LT 2 cysD-36 of Salmonella typhimurium. Thus, in both species the transmission of coll factor in mixed cultures in aerobic static broth took place mainly in the period of slow post-logarithmic growth, and in the case of both species there was evidence that this transmission involved an extensive 'epidemic' spread of the colI factor within the acceptor population, i.e. from freshly infected acceptor bacteria, to other acceptor bacteria. In both species, too, transmission was almost completely absent when the mixed cultures were aerated by continuous agitation. A difference in behaviour between the species was noted in our failure to obtain an HFC preparation of $\boldsymbol{S}$. flexneri that contained a high proportion of colicinogenic organisms after $2 \mathrm{hr}$ of secondary incubation of the mixture of the original donor and the intermediate strain. Since, however, Stocker et al. also failed to obtain a high proportion of colicinogenic organisms in such cultures when they used a non-motile mutant of $S$. typhimurium as the intermediate strain, our poor result with non-motile $S$. flexneri is not surprising. Ozeki et al. and Stocker et al. did not use any Fim- $^{-}$strain or any proven non-fimbriate-phase culture of $S$. typhimurium, so that it is not known whether the presence of fimbriae in the acceptor bacteria promotes transmission of colI in $S$. typhimurium in the same way as it does in S. flexneri.

The reason why transmission of colI is promoted by the presence of fimbriae in Shigella flexneri acceptors has not been determined. The finding that fimbriae (of the ordinarily demonstrable kind) are not essential for transmission makes it seem unlikely that they act as specific organs for transfer and intromission of the colI factor. It may be, however, that they facilitate the adhesion and conjugation of organisms as a necessary preliminary to transfer. There is good evidence to show that fimbriae have the effect of causing bacteria to adhere to various kinds of animal, plant and fungal cells, but none to show that they cause bacteria which are submerged in a liquid medium to adhere to one another. On the other hand, it has been found that the presence of fimbriae in $S$. flexneri organisms causes these, when cultured in aerobic static broth, to grow aggregated together in large numbers in a 
pellicle that appears on the surface of the broth after incubation for about $10 \mathrm{hr}$ (Duguid \& Gillies, 1957); some Fim- strains also may form a pellicle, but they do this at a later stage in culture, e.g. after 2-3 days. It may be supposed that the aggregation of fimbriate bacteria in a pellicle increases the opportunity for conjugation and transfer of colI between them. That pellicle formation is indeed responsible for the high rate of transfer obtained in crosses with fimbriate acceptors is suggested by our finding that relatively few acceptor bacteria became colicinogenic in mixed cultures in which pellicle formation was prevented by gentle shaking at intervals of $1 \mathrm{hr}$.

Another way in which fimbriation may help to promote transfer of coll is by its increasing, through the effect of pellicle formation, the amount of growth during the post-logarithmic phase in the mixed culture. Duguid \& Wilkinson (1961, see fig. 3) found that in fimbriate-phase cultures of Shigella flexneri strain 1 lal in aerobic static broth the total count of bacteria increased sevenfold between the 6 th $\mathrm{hr}$ of incubation, when logarithmic growth ended, and the $48 \mathrm{hr}$. In non-fimbriate-phase cultures the corresponding increase was only twofold. Since the transmission of colI in mixed cultures takes place mainly in the post-logarithmic period, it is understandable that the better growth given in this period by fimbriate as compared with non-fimbriate acceptor bacteria, may favour a higher rate of acquisition of coll.

If, as has been suggested, fimbriae promote transfer of colI through their effects in causing the aggregation and conjugation of bacteria in a pellicle and in increasing the amount of post-logarithmic growth, it may be asked why it is only the acceptor's fimbriation status that is important and why high rates of transfer are obtained with non-fimbriate donors. A possible explanation of the relative unimportance of the fimbriation status of the donor is afforded if we accept the conclusion, suggested by the experiments in which donors were killed by addition of streptomycin after $8 \mathrm{hr}$, that a high rate of transfer is the result of an extensive epidemic spread of colI among the acceptor bacteria. In a cross of non-fimbriate donor bacteria with fimbriate acceptor bacteria a few acceptor bacteria must first acquire colI from the non-fimbriate donors. Subsequently, coll may be transmitted freely from one fimbriate acceptor bacterium to another during the prolonged period of their postlogarithmic growth in the surface pellicle. This spread of colI would be little affected by the failure of the original non-fimbriate donor bacteria to participate equally in the post-logarithmic and pelliculate growth.

We wish to thank Dr B. A. D. Stocker for providing us with strains and for much helpful advice and criticism. M. M. was the holder of a British Council Scholarship.

\section{REFERENCES}

Aвbott, J. D. \& Shannon, R. (1958). A method for typing Shigella sonnei using colicine production as a marker. J. clin. Path. 11, 71.

Brinton, C. C., Gemski, P. \& Carnahan, J. (1964). A new type of bacterial pilus genetically controlled by the fertility factor of $E . c o l i \mathrm{k} 12$ and its role in chromosome transfer. Proc. natn. Acad. Sci. U.S.A. 52, 776.

Crawford, E. M. \& Gesteland, R. F. (1964). The adsorption of bacteriophage R-17. Virology 22, 165.

Duguid, J. P. \& Gillies, R. R. (1957). Fimbriae and adhesive properties in dysentery bacilli. J. Path. Bact. 74, 397. 
Dugum, J. P. \& Wilkinson, J. F. (1961). Environmentally induced changes in bacterial morphology. Symp. Soc. gen. Microbiol. 11, 69.

Duguid, J. P., Smith, I. W., Dempster, G. \& Eomunds, P. N. (1955). Non-flagellar filamentous appendages ('fimbriae') and haemagglutinating activity in Bacterium coli. J. Path. Baci. 70, 335.

FredericQ, P. (1954). Transduction génetique des proprietés colicinogénes chez Escherichia coli et Shigella sonnei. Séanc. C. r. Soc. Biol. 148, 399.

FredericQ, P. (1957). Colicins. A. Rev. Microbiol. 11, 7.

FredericQ, P. (1963). On the nature of colicinogenic factors: a review. J. theoret. Biol. 4, 159.

Lederberg, J. (1952). Cell genetics and hereditary symbiosis. Physiol. Rev. 32, 403.

Mulczyк, M. (1960). Studies on antigenic variability of Shigella flexneri 1b. Archrem. Immun. Terap. dośrwiad, 8, 1.

Ozeki, H., Howarth, S. L. \& Clowes, R. C. (1961). Colicine factors as fertility factors in bacteria. Nature, Lond. 190, 986.

Ozeki, H., Stocker, B. A. D. \& SMith, S. M. (1962). Transmission of colicinogeny between strains of Salmonella typhimurium grown together. J. gen. Microbiol. 28, 671.

Stocker, B. A. D., Sмiтн, S. M. \& OzeкI, H. (1963). High infectivity of Salmonella typhimurium newly infected by the colI factor. J. gen. Microbiol. 30, 201. 